\title{
A Pandemic of Webinars in the COVID Era-Can It be the Way Forward?
}

\author{
Senthilvelan Thenmozhi ${ }^{1}$ Subramanian Girija ${ }^{1} \quad$ K. Neelakantan Viswanathan ${ }^{1}$ \\ Aritakulu Kuppuswamy Badrinath ${ }^{1}$ \\ ${ }^{1}$ Department of General Medicine, Sri Manakula Vinayagar Medical \\ Address for correspondence Subramanian Girija, MBBS, DNB, \\ College and Hospital, Puducherry, India \\ Department of General Medicine, Sri Manakula Vinayagar Medical \\ College and Hospital, Puducherry 605 107, India \\ J Health Allied Sci ${ }^{\mathrm{NU}} 2022 ; 12: 398-406$. \\ (e-mail: girijagops@gmail.com).
}

\begin{abstract}
Introduction Conferences are important and sometimes mandatory to update the clinician with latest knowledge. Attending conferences requires planning, expenditure, and leave from work. Webinars have become the new normal in the coronavirus disease (COVID) era. We surveyed the esteemed medical fraternity on their opinion on webinars.

Methods This was conducted as an online survey (Survey Monkey) through personal electronic mails and social media with 24 questions. Details on demographic profile, specialization and affiliation, experience, choice of frequency of webinar sessions, suitable platform, mode of intimation of webinars, number of days for prior intimation, appropriate timing of the day and week, and ideas on payment options were enquired. Need for technical assistance, choice of topic for discussions methods to make webinars more interactive, availability of recorded content, and impact on clinical practice were also assessed.

Results A total of 235 medical professionals voiced their opinion; $67 \%$ were $<35$ years of age and $49 \%$ were residents. An average of 2 to 3 webinars per month (33.8\%), conducted on weekdays (63\%), after 6 p.m. (54\%) in the form of case discussion (67.3\%) or lectures from experts (55\%) with at least 7 days' notice $(41.7 \%$ ) was the most common choice; free webinars were the wish of $56.1 \%$ participants and $28 \%$ felt
Keywords
- webinar
- COVID-19
- education
- conference webinars would definitely impact practice.

Conclusion Webinars are welcoming even after the COVID era and should go hand-inhand with conventional conferences. Virtual learning experience should be optimized by proper scheduling of multiple simultaneous events and converting them into interlinked or serial events.
\end{abstract}

\section{Introduction}

Conferences and continuing medical education (CME) events help the clinician to keep themselves abreast with the latest developments. They are even deemed mandatory by some professional bodies. This, however, needs planning leave from work, expenditure, and travel which makes it impossible for many professionals to attend, though interested. ${ }^{1}$ Webinars are a boon to these practicing professionals. published online

February 11, 2022
DOI https://doi.org/ $10.1055 / \mathrm{s}-0042-1742465$. ISSN 2582-4287.

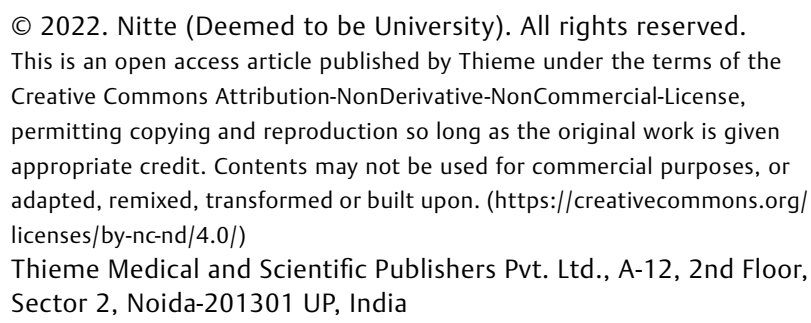


Webinars have suddenly become contagious and virtually pandemic in all medical fields in the coronavirus disease (COVID) era. The Internet platforms have made it accessible to attend webinars from our homes or workplace during the lockdown period. This opportunity was utilized to assess the esteemed opinion of the medical fraternity on webinars as way forward for education.

\section{Methods}

This was conducted as an online survey using Survey Monkey Web site. The participants were medical professionals belonging to various clinical fields of tertiary care institutes of South India. Institute research and ethics committee clearance was obtained. The survey was sent through personal electronic mails, WhatsApp, and Twitter. This survey had 24 questions grouped under the following headings (Appendix 1):

A. Demographics, practice, and experience:

We recorded age and gender of participants, their field of specialization, affiliation, number of years of experience after their highest academic degree, and the number of academic sessions at their work place.

B. Haunt for academics:

We enquired the interest of respondents on their choice for frequency of webinar sessions, suitable and comfortable platform for webinars, mode of intimation of webinars, number of days for prior intimation, preference for weekdays or weekends, appropriate timing, and their ideas on payment options. We also enquired how many participants felt they need technical assistance to attend webinars.

C. Expectations from webinars:

We surveyed the choice of types and topics for discussions, the need for recording of sessions, and ways to make webinars more interactive. The impact of webinar-acquired knowledge on clinical practice and how much knowledge they could gain from webinars in comparison with conventional conferences were assessed. In view of multiple events happening simultaneously, we also enquired how they wanted to regulate these events.

D. Residents' view:

We enquired residents specifically about their ideas on academic discussions and grand rounds at reputed educational centers.

\section{Statistical Analysis}

The results were acquired in Microsoft Excel from Survey Monkey. It was recoded to Statistical Package for Social Sciences (SPSS v20.0). Discrete variables were represented as frequencies and percentages. Questions carrying open-ended answers were categorized and tabulated as frequencies.

\section{Results}

\section{Demographics, Specialty, and Experience}

A total of 235 medical professionals participated in the survey at an average time of 6 minutes and 20 seconds to complete the survey. The survey population was dominated by male doctors
$(144 ; 61.28 \%)$. Majority $(159 ; 67.65 \%)$ of the respondents were aged $<35$ years, followed by 65 (27.66\%) in the 35 to 50 years' category and $11(4.68 \%)$ participants were $>50$ years old. Majority $(161 / 235 ; 68.51 \%)$ of the study population was contributed by medical specialists, 74 (31.49\%) participants belonged to surgical specialties. Residents contributed to 115 (48.94\%) of study population (235 respondents), 76 (32.34\%) were consultants, and $44(18.72 \%)$ were teaching faculty. Among those who completed residency $(N=132)$, majority ( $72 ; 54.55 \%)$ of the participants were from institutional setup, $48(37.8 \%)$ were working in private multispecialty hospitals, and 12 (8.66\%) were private practitioners. Out of 235 respondents, 90 (38.3\%) had a minimum of 2 to 3 academic session per week in their work place, $62(26.4 \%)$ had 4 to 6 sessions per week, 57 (24.3\%) had $<1$ session per week, and 26 (11\%) were having $\geq 7$ sessions per week ( - Table $\mathbf{1}$ ).

\section{Accessibility, Convenient Timing, and Scheduling}

Not to our surprise, around 150 (63.83\%) participants were confident of handling Internet access to attend webinars and 66 (28.09\%) required little support. Complete assistance was needed for 7 (2.98\%) participants while $12(5.11 \%)$ were not interested in attending virtual sessions (-Fig. 1A). Majority of participants $(152 ; 64.68 \%$ ) were comfortable in using the Zoom platform for webinars and individual Web site links (36; $15.32 \%)$.

When asked regarding the optimal number of webinar sessions per month, 80 (34\%) chose 2 per month, 60 (25.6\%) were ready to attend $>3$ per month, 59 (25.1\%) were comfortable with 3 sessions per month, and 36 (15.3\%) felt it was suitable to have 1 session per month (-Table 1). Participants doing residency and from educational institutes were willing to attend more $(p=0.004)$ webinar sessions per month (-Table 2).

The most convenient time of the day as felt by 127 (54\%) of participants was after 6 p.m., followed by 87 (37\%) were ready to attend during working hours, 25 (10.7\%) wanted late night sessions, and $19(8.3 \%)$ wanted sessions to be conducted before working hours ( - Table 1 ). Proportion of participants opting for sessions after 6 p.m. was higher among those in private practice. Weekdays were preferable for majority (144; $61.5 \%$ ) of participants, followed by Saturdays (59; 25.2\%) and Sundays ( $55 ; 23.4 \%) ; 19$ (8.1\%) were willing to attend sessions on public holidays (multiple options) (-Table 1). Weekdays were preferred $(p=0.001)$ by residents and specialists in private setup.

\section{Preferences, Communication, Interaction, and Fees}

Regarding the best way forward for knowledge sharing, majority $(133 ; 56.6 \%)$ felt webinars on individual topics were the best, while 88 (37.45\%) still thought conventional conferences, 86 (36.60\%) thought virtual CME, and online training sessions by 70 (30.7\%) participants. Regarding the type of discussions (multiple options), 158 (67.2\%) participants wanted case discussions and 128 (54.5\%) wanted lectures from field experts as their first and second preferences, followed by CME on advanced topics (83; 35.3\%) and lectures on allied subjects $(82 ; 34.9 \%)$ (-Table 1$)$. 


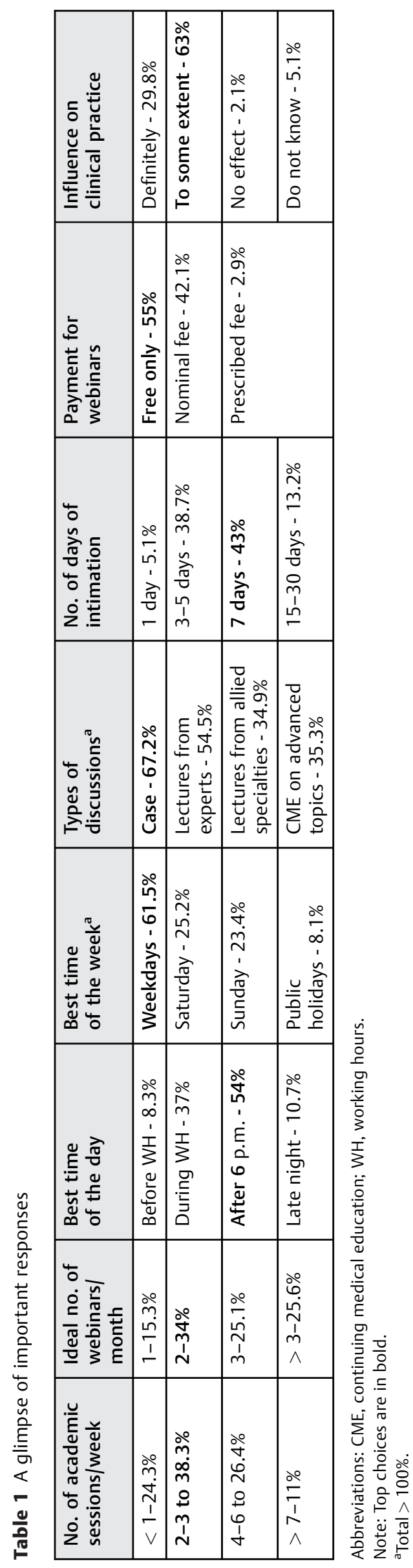

While enquired how to overcome the problem of multiple simultaneous events, a common mailing/WhatsApp group was the first choice of communication for webinar invitations from different specialties by 103 (43.83\%) participants and multichannel managers to organize multiple simultaneous webinar events was the choice in 45 (19.15\%) participants. Also, 71 (30.21\%) thought it was solely the participants' choice to attend webinars of their interest and 16 (6.81\%) felt it was difficult to integrate simultaneous sessions. Private practitioners felt it was the decision of participants to attend their events of choice while a common group to communicate regarding multiple events was the choice of residents and members from institutional practice $(p=0.008)$ (-Table 2). Most $(101 ; 43 \%)$ participants felt they would be able to plan their attendance if intimated before 1 week, followed by 3 to 5 days $(91 ; 38.7 \%$ ) (-Table 1 ). Residents were ready to attend the webinars with an intimation of 3 to 5 days prior, while other participants preferred a 7-day intimation time $(p=0.045)$ (-Table 2).

Majority $(129 ; 55 \%)$ of the participants opted for free webinars, 99 (42.1\%) were willing to pay nominal fees, and only $7(2.9 \%)$ opted to pay the prescribed fees (-Table $\mathbf{1}$ ). Residents were not alacritous enough to pay fees for webinars $(p=0.001)$ when compared with those from institutional and private setup ( - Table 2 ). Regarding recordings of sessions, $110(46.81 \%)$ of the participants felt that it should be given to all those who are interested for free, 101 (42.98\%) wanted it to be distributed to all for free.

To make webinars interactive, most $(104 ; 44.26 \%)$ of the participants chose to type their questions in the chat box so that they can be taken up by a moderator at the appropriate time and not to interrupt in the flow of presentation while 99 (42.13\%) preferred questions to be taken up at the end of session and 25 (10.64\%) wanted questions to be addressed (like symposium) during sessions by unmuting their microphones (-Fig. 1B).

\section{Applicability and Utility}

When enquired how much knowledge the participants could gain, 101 (42.98\%) felt that they could grasp as much information from a webinar as from conventional conferences and $95(40.43 \%)$ felt that it was possible to some extent while 39 (16.60\%) participants felt that conventional conferences were better than webinars (-Fig. 1C). Majority (148; 63\%) of the participants thought that webinars will influence their clinical practice to some extent, $29.8 \%$ (70) felt it is bound to impact, and $2.1 \%$ (5) felt would not affect clinical practice while $5.1 \%$ (12) did not know the effect of webinars on their clinical practice (-Table 1). Around $82.5 \%$ (85/103) of residents preferred attending academic meets and grand round through webinars at reputed hospitals signifying their thirst for national and international outreach.

\section{Special Interests}

The participants felt that the following points could have been addressed in the survey-fixing time duration for webinars, webinar sessions on newer guidelines and treatment protocols with journal appraisals, and local trends of 

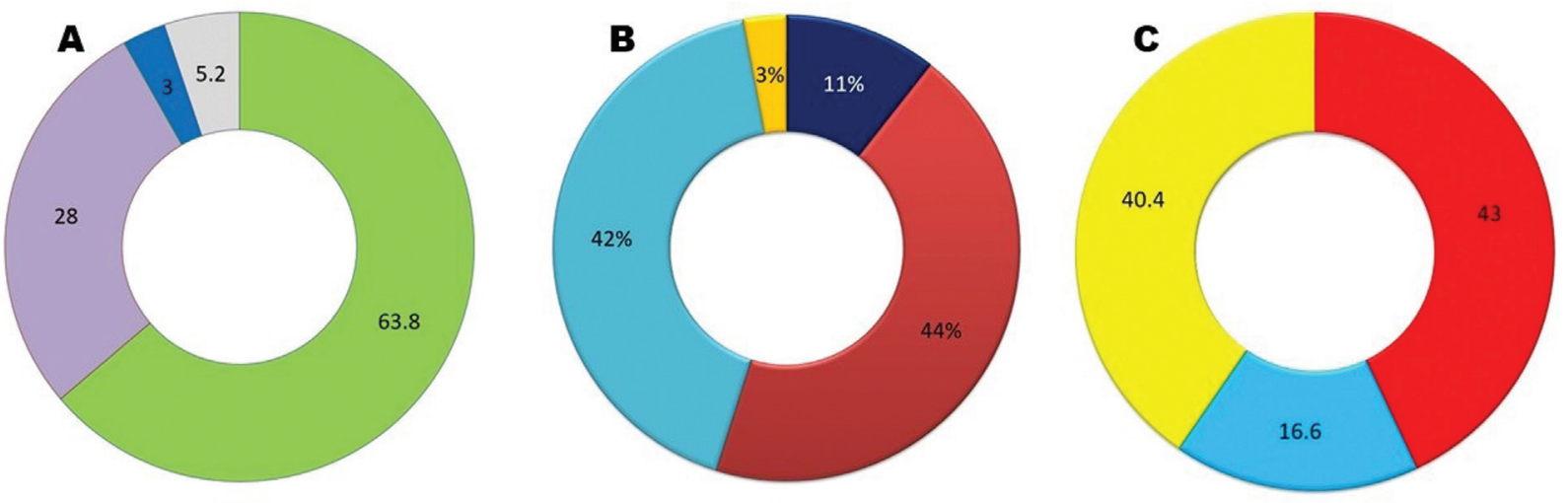

aself-reliant a Need some support ENeed assistance to do aNot interested
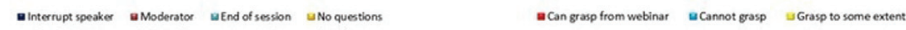

Fig. 1 (A) Proportion of doctors requiring assistance to attend a webinar. (B) Ways to make the webinars more interactive. (C) Level of grasping as felt by the participants in online vs. conventional programs.

Table 2 Ideal timing, prior intimation, number of webinars, and payment options across practice groups

\begin{tabular}{|c|c|c|c|c|c|}
\hline Question & Options & $\begin{array}{l}\text { Residents } \\
(N=103) \\
N(\%)\end{array}$ & $\begin{array}{l}\text { Educational } \\
\text { institutes } \\
(N=72) \\
N(\%)\end{array}$ & $\begin{array}{l}\text { Individual practice + Private } \\
\text { hospitals }(N=60) \\
N(\%)\end{array}$ & $p$-Value \\
\hline \multirow{4}{*}{$\begin{array}{l}\text { Ideal number } \\
\text { of webinars }\end{array}$} & $1 / \mathrm{mo}$ & $8(7)$ & $12(16.7)$ & $16(26.7)$ & \multirow[t]{4}{*}{0.004} \\
\hline & $2 / \mathrm{mo}$ & $36(34.9)$ & $22(30.6)$ & $22(36.7)$ & \\
\hline & $3 / \mathrm{mo}$ & $30(29.1)$ & $14(19.4)$ & $15(25)$ & \\
\hline & $>3 / \mathrm{mo}$ & $29(28.2)$ & $24(33.3)$ & $7(11.6)$ & \\
\hline \multirow{4}{*}{$\begin{array}{l}\text { Number of days for } \\
\text { prior intimation }\end{array}$} & $1 \mathrm{~d}$ & $6(5.8)$ & $5(6.9)$ & $1(1.7)$ & \\
\hline & $3-5 d$ & $49(47.6)$ & $22(30.5)$ & $19(31.7)$ & 0.045 \\
\hline & $7 d$ & $35(33.9)$ & $35(48.6)$ & $32(53.3)$ & \\
\hline & $15-30 d$ & $13(12.6)$ & $10(13.8)$ & $8(13.3)$ & \\
\hline \multirow{4}{*}{$\begin{array}{l}\text { Integrating multiple } \\
\text { simultaneous webinars }\end{array}$} & Common group & $54(52.4)$ & 27 (37.5) & $22(36.7)$ & \multirow[t]{4}{*}{0.008} \\
\hline & Not possible & $11(10.6)$ & $4(5.5)$ & $1(1.7)$ & \\
\hline & Choice & $28(27.2)$ & $23(31.9)$ & $20(33.3)$ & \\
\hline & $\mathrm{MCM}$ & $10(9.7)$ & $18(25)$ & $17(28.3)$ & \\
\hline \multirow{3}{*}{$\begin{array}{l}\text { Willingness to } \\
\text { pay for webinars }\end{array}$} & Not at all & $64(62.1)$ & 40 (55.5) & $25(41.7)$ & \multirow[t]{3}{*}{0.001} \\
\hline & Nominal fee & $39(37.9)$ & $31(43.1)$ & $28(46.7)$ & \\
\hline & Prescribed fee & 0 & $1(1.4)$ & 7 (11.6) & \\
\hline
\end{tabular}

Abbreviation: MCM, multichannel managers.

diseases. Participants suggested that short sessions by speakers with take-home messages, with pre- and postsession quiz and postsession compliments can make these sessions livelier and interactive.

\section{Discussion}

Seminar (Latin: seminarium - seed plot) is a form of academic teaching for discussions or trainings. In seminars we know our audience and adapt our level of knowledge for learners. ${ }^{1}$ Conferences help acquaintance among residents and fellows. It can foster engagement with leading global experts and obtain their opinions on progress on contemporary research. ${ }^{2}$ Attending seminars need lot of preplanning and perfectly harmonized organization. However, it restricts the number of participants.

Though there has been reemergence of webinars, in-person academics are still cherished as an important component of education. Face-to-face meetings will be conducted under duress Web-based platforms till it is deemed safe to travel. Till recently, replacing conventional conferences with Webbased conferences and lectures at the comfort of their homes or offices was never on the horizon and this unprecedented pandemic has paved way for this opportunistic teachinglearning transition. ${ }^{3}$ Indisputably, Web-based events also need a lot of background organization. ${ }^{2}$ Webinars are open for worldwide viewing, straightforward to access, even during duty hours and it is convenient in all aspects, it should satisfy 
knowledge needs of participants from all levels. As webinars have become a new normal in the COVID era, the same has been reiterated by most participants. Webinars are replete with information on current research and multidisciplinary approach. $^{4}$

\section{Education-Classroom Teaching and Conferences}

There are two aspects of resident education, viz., classroom teaching and conferences. ${ }^{2}$ Fellows and consultants have been deputed to lead the battle against COVID, practical clinical demonstrations, surgical training, and conventional lectures that are vital to medical education and academics have been paused temporarily. ${ }^{3}$ Mishra et al reported a surge in the total number of online events in ophthalmology with the imposing of lockdown and $75.7 \%$ of ophthalmologists felt this a useful tool for education. Education has adapted itself to remote mentoring, podcasts, online clinical vignettes, and tweetorials. ${ }^{2}$ Also to meet "social distancing" requirements, many conferences have been cancelled or postponed.

\section{Scheduling Webinars}

Though webinars can be attended from the homes or offices of doctors and it does not demand off from work, participation still needs lot of preplanning. The attendees must reorganize their clinical work to devote time for online events. While conventional conferences need 1 to 6 months of preparation time, at least 1 week prior notice was necessary to ensure adequate participant attendance. Residents of Chile felt overloading of online activities as a significant problem as also evidenced from our responses. ${ }^{3}$ Though $88.7 \%$ of residents had regular academic sessions, residents felt webinar-based learning could also provide a platform to the much needed international exposure.

\section{Internet and Ambient Environment}

The major challenge in a seamless experience in webinarbased education is the availability of powerful Internet services. In a recent report from Chile, technical problems were reported despite having high-speed Internet services, similar to that reported by previous studies also., 3,6 The next important challenge is the importance of ambience and appropriate environment in the attendees' home or office and avoiding distractions. Time has to answer if residents will continue to believe in online learning once the pandemic is over and treat it over conventional learning tools. It was felt that some element of face-to-face teaching, small groupbased activities should be incorporated and completely virtual medical education was not fully acceptable. ${ }^{7}$

\section{Transition to Online}

Many centers have transitioned to online classes. Smart learning, telementoring, and telemedicine have been the new norms of education. The time available for smart learning is based on proportion of residents and time, posted for COVID duties. ${ }^{8}$

\section{Future Trends}

While webinars certainly are an innovative and indispensable tool during the COVID pandemic and it has provided unrestricted access to educational activities, there is still lot of work to do to make it a complete educational tool. Virtual learning has its own limitation to impart operative skills. ${ }^{1}$ Interactive virtual tools may help in improving the online experience. $^{9-11}$ Webinars can foster international level of discussions for residents and upcoming specialists. Credit points for virtual learning events, accessing the interest of participants during the webinars by artificial intelligence, continual improvement to suit the need of the client, and making them more interactive can go a long way in making webinars the new way forward.

\section{Conclusion}

Webinars are certainly a boon in the present COVID era and is likely to persist even after the pandemic is over. Virtual learning should go hand-in-hand with conventional learning tools like conferences to provide maximum benefit to trainees and practitioners. Optimization of the virtual learning experience by clutter free scheduling, fixing timeline for sessions, and improvement in accessibility of Internet services and platforms can boost the success of virtual learning.

\section{Disclaimers \\ None.}

Source(s) of Support in the Form of Grants, Equipment, Drugs Not applicable.

Conflict of Interest

None declared.

\section{References}

1 Ali SR, Dobbs TD, Whitaker IS. Webinars in plastic and reconstructive surgery training - a review of the current landscape during the COVID-19 pandemic. J Plast Reconstr Aesthet Surg 2020;73 (07):1357-1404

2 Mishra D, Nair AG, Gandhi RA, et al. The impact of COVID-19 related lockdown on ophthalmology training programs in India - outcomes of a survey. Indian J Ophthalmol 2020;68(06): 999-1004

3 Figueroa F, Figueroa D, Calvo-Mena R, Narvaez F, Medina N, Prieto J. Orthopedic surgery residents' perception of online education in their programs during the COVID-19 pandemic: should it be maintained after the crisis? Acta Orthop 2020;91 (05):543-546

4 Chua A Jr, Mendoza MJ, Ando M, et al. Changing the landscape of medical oncology training at the national university hospital in the Philippines during the coronavirus disease 2019 (COVID-19) pandemic. J Cancer Educ 2020 Jun 5:1-3

5 Horstmann M, Renninger M, Hennenlotter J, Horstmann CC, Stenzl A. Blended E-learning in a Web-based virtual hospital: a useful tool for undergraduate education in urology. Educ Health (Abingdon) 2009;22(02):269

6 Jayakumar N, Brunckhorst O, Dasgupta P, Khan MS, Ahmed K. eLearning in surgical education: a systematic review. J Surg Educ 2015;72(06):1145-1157

7 Funke K, Bonrath E, Mardin WA, et al. Blended learning in surgery using the Inmedea Simulator. Langenbecks Arch Surg 2013;398 (02):335-340 
8 Amparore D, Claps F, Cacciamani GE, et al. Impact of the COVID-19 pandemic on urology residency training in Italy. Minerva Urol Nefrol 2020;72(04):505-509

9 Zingaretti N, Contessi Negrini F, Tel A, Tresoldi MM, Bresadola V, Parodi PC. The impact of COVID-19 on plastic surgery residency training. Aesthetic Plast Surg 2020;44(04): 1381-1385
10 Ekstrand C, Jamal A, Nguyen R, Kudryk A, Mann J, Mendez I. Immersive and interactive virtual reality to improve learning and retention of neuroanatomy in medical students: a randomized controlled study. CMAJ Open 2018;6(01):E103-E109

11 Griffith SF, Hagan MB, Heymann P, Heflin BH, Bagner DM. Apps as learning tools: a systematic review. Pediatrics 2020;145(01): e20191579 


\section{Appendix 1}

\section{Opinion: Webinars as New Educational Tool}

Respected Sir/ Madam

There has been a recent upsurge in the number of webinars being conducted to spread knowledge.

By clicking the "OK" button, we consider that you have given your consent for the survey.

Thanking you,

Primary investigator name and designation

\section{Questions}

1. Which is your field

a. General Medicine

b. Dermatology

c. Psychiatry

d. Pediatrics/Pediatric superspecialty

e. Cardiology

f. Neurology

g. Endocrinology

h. Medical Gastroenterology

i. Hepatology

j. Nephrology

k. Hematology

1. Medical Oncology

m. Rheumatology

n. Immunology

o. Pulmonology

p. Diabetology

q. Radiology

r. Infectious Diseases

s. Anesthesia

t. Critical Care

u. Geriatric Medicine

v. Family Medicine

w. Surgical specialties/ Surgical superspecialties

x. Others

2. Age (in years)

3. Gender (Male/Female)

4. What is your affiliation

Resident

Consultant

Teaching faculty

5. No. of years of experience (post MD/DM) in years. Please skip if you are a resident.

6. Practice Type. Please omit if you are a resident.

Individual practice

Multispecialty/ Private Hospital with departmental setup

Institutional/ University setup as faculty

7. No. of Academic discussions per week in your present setup
a. $<1$
b. $2-3$
c. 4-6
d. $>7$ 
8. Which online platform was the most comfortable to attend a webinar

a. Zoom

b. Microsoft teams

c. Google meet

d. Facebook Live

e. Instagram Live

f. YouTube Live

g. Login from individual Web site through link

Please Comment: Why do you feel so?

9. How many e-sessions you think will be ideal

a. $<2 /$ month

b. $1 /$ week

c. $>2 /$ week

d. >7/week

10. What is the best time of the day to ensure your attendance?
a. Before working hours
b. During working hours
c. After 6 PM
d. Late night sessions

11. Which is the best time of the week to ensure your attendance?
a. Weekdays
b. Saturdays
c. Sundays
d. Public holidays

12. What type of discussions you are interested in

a. Case discussions

b. Lectures from field experts

c. Lectures from experts from allied specialties

d. CME on allied/ advanced topics

13. Which do you think is the best way to make webinars most interactive?

a. Interrupt the speaker by unmuting your microphone during the presentation (like a symposium)

b. Type the question in the comment box so that moderators can take up your question at the appropriate time (like a moderated symposium)

c. Questions should be taken at the end of the presentation (like a seminar)

d. There is no scope for questions (like an oration)

Please Comment: Why

14. Which do you think is the way forward for knowledge sharing
a. Conventional conferences
b. Webinar on individual topics
c. Online CME (Virtual CME)
d. Online training sessions

15. How many days in advance should a session be planned to ensure maximum attendance and participation?
a. 24 hours
b. 3-5 days
c. 7 days
d. 15-30 days

16. Do you think webinars can make you grab as much knowledge as you do from a conventional CME or conference?
a. Yes
b. No
c. To some extent 
17. There are many meetings happening from different specialties which can be relevant to you. How to integrate these invitations to ensure maximum availability across specialties?

a. Common mailing/ whatsapp group

b. Multi-channel managers (MCM) from broad/ superspecialties distributing schedule to others

c. It is purely by choice of the participants

d. It is not possible to integrate schedules of multiple specialties Please add a comment if any

18. Do you feel you need technical assistance and support in attending e-sessions?

a. Am confident of attending it myself

b. Have been attending but need some support

c. Have tried but not succeeded, need assistance

d. I am not interested in attending e-sessions

19. Do you think recording and distributing webinar content should be mandatory?
a. Definitely for free
b. To those interested for free
c. To those interested with payment
d. Not necessary to distribute

20. Are you ready to pay for online webinars/ conferences/CMEs?
a. Not at all, will watch if free
b. Willing to pay a nominal fee
c. Willing to pay prescribed fees Comment: if any

21. Do you think attending these online sessions will influence your clinical practice?

a. It is bound to make an impact

b. It will help me to some extent

c. It won't affect my clinical practice

d. Do not know

22. What exactly do you feel you need to get from a webinar which has not been addressed in this survey? Any other comments.

23. As a postgraduate, attending academic meets/ grand rounds at reputed hospitals as webinars, will they be useful?
a. Yes
b. No
Comments: if any

24. Please enter your email ID. 